\title{
Contextos (in)adequados para o engajamento cidadão no controle social
}

\author{
Marjorie Sabioni \\ Universidade Federal de Viçosa / Departamento de Administração e Contabilidade, Programa \\ de Pós-graduação em Administração \\ Viçosa / MG - Brasil \\ Marco Aurélio Marques Ferreira \\ Universidade Federal de Viçosa / Departamento de Administração e Contabilidade, Programa \\ de Pós-graduação em Administração \\ Viçosa / MG - Brasil \\ Marcelo José Braga \\ Universidade Federal de Viçosa / Departamento de Economia Rural, Programa de Pós- \\ graduação em Economia Aplicada \\ Viçosa / MG - Brasil \\ Fernanda Maria de Almeida \\ Universidade Federal de Viçosa / Departamento de Administração e Contabilidade, Programa \\ de Pós-graduação em Administração \\ Viçosa / MG - Brasil
}

\begin{abstract}
Esse trabalho partiu de um quadro bibliográfico sobre a influência do contexto nos objetos de análise, para compreender as características e as condições de atuação dos cidadãos nos municípios de Minas Gerais, visando abranger os aspectos que contribuem para a criação de um ambiente favorável à participação democrática. Por meio da análise fatorial, foi possível apontar três fatores importantes para a atuação cidadã nos municípios: estrutura municipal, contexto institucional e mobilização social. A partir dessas informações, construiu-se um índice que permitiu determinar os municípios mais ou menos favoráveis à participação. Os resultados reforçam a necessidade de se estabelecerem prioridades no sentido de apoiar os municípios que se encontram em situações menos favoráveis, para que seus cidadãos possam ser efetivamente envolvidos e colaborem com soluções adequadas para o local onde residem.

Palavras-chave: controle social; engajamento cidadão; contexto municipal; administração pública.
\end{abstract}

DOI: http://dx.doi.org/10.1590/0034-7612153518

(c) (1)

Artigo recebido em 20 ago. 2015 e aceito em 9 mar. 2016.

Rev. Adm. Pública - Rio de Janeiro 50(3):477-500, maio/jun. 2016 


\section{Contextos (en)adecuados para la participación ciudadana en el control social}

Este trabajo proviene de una bibliográfica acerca de la influencia del contexto en el análisis de los objetos, para comprender las condiciones para las acciones de los ciudadanos en los municipales de Minas Gerais, con el objetivo de abarcar los aspectos que contribuyen a la creación de un entorno propicio para la participación democrática. Mediante análisis de factores, fue posible señalar tres factores importantes para las acciones de los ciudadanos: Estructura Municipal, el Contexto Institucional y la Movilización Social. Se construyó un índice que permitió determinar los municipios más o menos favorables a la participación. Los resultados refuerzan la necesidad de establecer prioridades para apoyar a los municipios que se encuentran en situaciones menos favorables, de manera que sus ciudadanos puedan participar de manera efectiva con el fin de buscar soluciones para mejorar el lugar donde residen.

Palabras Clave: control social; participación ciudadana; contexto municipal; la administración pública.

\section{Contexts (un)suitable for citizens' engagement in social control}

This paper began with a bibliographic framework on the influence of context on the objects of analysis, to better understand the characteristics and the engagement of citizens in municipal areas of Minas Gerais state. The aim was to identify the aspects that contribute to the creation of an environment favorable to democratic participation. By using factor analysis, it was possible to point to three important factors relating to the engagement of citizens in these municipalities: the Municipal Structure, the Institutional Context and Social Mobilization. Based on this information, an index was devised that enabled one to determine the municipalities that were more or less favorable to such engagement by their residents. The study's results strengthened the arguments in favor of prioritizing in terms of supporting those municipalities in less favorable situations, thereby enabling their citizens to become effectively involved and consequently help in providing appropriate solutions to improve the municipal spaces in which they reside.

KEYWORDs: social control; citizens' engagement; municipal context; public administration.

\section{Introdução}

É consensual a importância da atuação cidadã no controle social da administração pública para o desenvolvimento de uma sociedade baseada na democracia. De acordo com Serra e Carneiro (2012), o controle social nada mais é que o engajamento do cidadão na avaliação das ações da gestão pública, de forma a verificar a realização de objetivos, processos e resultados, em prol do interesse da coletividade.

Sob essa ótica, o engajamento cidadão requer que os governos compartilhem a definição da agenda e garantam que as propostas políticas geradas em conjunto sejam consideradas na decisão final. A atuação cidadã é apropriada em todas as etapas do processo de desenvolvimento de políticas, sendo vista como um processo interativo, que serve para infundir os valores e as prioridades dos cidadãos em todo o ciclo político (Sheedy, 2008).

O controle social exercido por meio do engajamento cidadão ocorre, principalmente, em nível municipal. Isso porque a ação do poder público é mais aparente nesse espaço, seja 
referente à condição institucional para a oferta de políticas públicas voltadas para a população residente, seja com relação aos seus resultados demonstrados (Castro, 2003).

Nesse sentido, os municípios têm ganhado cada vez mais importância no país devido aos seus papéis na oferta direta de bens e serviços públicos, no estímulo à cidadania, por meio da promoção de diversas práticas de envolvimento da sociedade na administração pública, e no incentivo ao desenvolvimento socioeconômico dos residentes de seu território (Klering e Schröeder, 2008).

No entanto, o Brasil é um país caracterizado por fortes disparidades, tanto relacionadas com povoamento, atividades econômicas, distribuição de renda e educação quanto com dimensões variadas dos municípios, tais como territoriais, políticas, estruturais, entre outras. Essa distinção é pertinente, também, quanto ao arranjo de equipamentos sociais disponíveis à sociedade e aos aspectos dos espaços políticos, condições essenciais para que a cidadania seja exercida (Castro, 2003). Nesse contexto, Minas Gerais é um dos estados brasileiros marcados por intensas desigualdades em seu território, apresentando estruturas socioeconômicas significativamente diferentes, sobretudo no que se refere à atividade econômica e às condições de saúde e emprego (Costa et al., 2012).

Assim, é relevante discutir o engajamento cidadão no controle social em Minas Gerais, já que esse é um dos aspectos que influem no desenvolvimento de uma sociedade justa e democrática. Conhecer os aspectos que colaboram para efetiva atuação no controle social permite aperfeiçoar as políticas e os programas públicos, adequando-os à realidade local, evitando, portanto, efeitos contrários aos desejados e à manutenção das desigualdades.

A ampliação do exercício do controle social dentro da administração pública municipal torna-se crucial para facilitar a visualização de objetivos comuns em torno de propósitos de desenvolvimento local e regional. Uma vez que a administração para o desenvolvimento é um processo dinâmico, constante, conflitante e incompleto, entende-se que são necessários vitalidade, compromisso cívico de seus atores e engajamento dos cidadãos (Filippim, Rossetto e Rossetto, 2010).

Desse modo, este trabalho busca compreender o contexto dos municípios do estado de Minas Gerais, isto é, as características desses espaços de atuação dos cidadãos, visando abranger quais são os aspectos que contribuem para a criação de um ambiente favorável. Diante do exposto, cabe introduzir a questão que norteia este estudo: Como diferentes características do contexto municipal contribuem para o engajamento dos cidadãos no exercício do controle social?

O principal propósito deste estudo foi identificar o potencial para a atuação cidadã na administração pública, proporcionada pelas características dos municípios mineiros, mediante um conjunto de variáveis agregadas em um índice que permita conhecer os fatores que expliquem as diferenças no exercício do controle social, e que possibilite hierarquizar os municípios em termos de ambientes mais ou menos favoráveis à participação.

A expectativa é que a construção dessa medida de desempenho seja vista como um mecanismo que forneça subsídios para o aprimoramento dos programas públicos existentes, que visam promover o controle social no país, além de auxiliar as esferas municipal, estadual e federal a refletir e trabalhar conjuntamente, almejando construir ambientes que favoreçam 
a participação cidadã. Por conseguinte, espera-se que esta investigação contribua para o fortalecimento da gestão pública municipal e maximize o engajamento cidadão no controle social, de forma que possibilite uma gestão compartilhada que beneficie a população por meio da redução das desigualdades.

\section{Revisão bibliográfica}

\subsection{0 papel do contexto na implementação de programas públicos}

A falta de conhecimento pelos avaliadores e decisores políticos do contexto em que os programas são implementados, associada a uma abordagem demasiadamente generalizada, pode dificultar a capacidade de um programa atingir seu público-alvo e stakeholders (Wond e Macaulay, 2010). O contexto é a forma como o programa funciona dentro do ambiente econômico, social e político de sua comunidade, abordando questões que exploram os relacionamentos e a capacidade do programa, visando auxiliar na identificação de alguns pontos fortes e fracos, bem como o efeito de influências imprevistas e externas sobre o programa (W. K. Kellogg Foundation, 2004).

Nesse sentido, é sabido que as intervenções podem apresentar três tipos de aspectos: simples, complexos e complicados. A análise das características contextuais é imprescindível especialmente em programas que apresentam aspectos complicados. A maioria dos desenvolvimentos de intervenções tem aspectos complicados, apresentando vários componentes que são necessários para produzir os resultados pretendidos. É possível planejar em detalhes a implementação de uma intervenção, mas requer considerável experiência e coordenação de diferentes componentes, e programas funcionam de forma diferente em situações diferentes (Rogers e Hummelbrunner, 2012).

De acordo com Bamberger e Segone (2011), o quadro contextual deve conter a análise dos fatores socioculturais, ambientais, políticos, econômicos, legais, institucionais, entre outros, que afetam a forma como os programas são implementados e como alcançam os seus resultados. Todos esses fatores podem limitar a implementação eficaz das intervenções. Em casos em que há pouco apoio social ou político para a integração de grupos desfavoráveis, muitos desses fatores podem apresentar grandes desafios. Enquanto aspectos contextuais são muitas vezes analisados de forma descritiva, também é possível incorporar essas variáveis na análise estatística.

Esses autores ainda salientam que o desenvolvimento de programas pode ser afetado por uma ampla gama de aspectos contextuais locais, regionais e nacionais, que incluem os fatores políticos, econômicos, organizacionais, institucionais, administrativo-legais e ambientais. Já Kegler e colaboradores (2011) incluem também outros domínios contextuais tais como a história de colaboração, geografia, demografia, valores e normas da comunidade, e história comunitária. Para facilitar a análise desses aspectos, podem ser estabelecidos indica- 
dores mensuráveis de fatores contextuais, que incluam uma definição clara de seu efeito sobre a implementação e os resultados da política (Bamberger e Segone, 2011).

Os profissionais e avaliadores devem ter tempo para refletir sobre os aspectos contextuais que podem influenciar o sucesso de seu trabalho. Alguns desafios que podem surgir a partir de barreiras contextuais podem ser evitados ou mitigados com um planejamento cuidadoso e atenção, como divulgação especial, localização estratégica das atividades do programa, atenção ao modo como os problemas e as soluções são enquadradas, recrutamento deliberado de representantes de segmentos da comunidade não tipicamente envolvidos etc. Já outros aspectos do contexto da comunidade podem simplesmente ser aproveitados de forma positiva, como conexões entre organizações e pessoas que colaboraram no passado, a construção estratégica de valores em comum que podem incentivar uma ampla gama de pessoas e organizações a participarem (Kegler et al., 2011).

Considerando que este estudo visa compreender como os aspectos contextuais contribuem para a participação no controle social, tem-se o artigo de Abelson e colaboradores (2007), que buscaram documentar e interpretar o papel de múltiplos contextos na formação do desenho, da implementação e da avaliação de processos de envolvimento público. Esses autores afirmam que a atenção para os atributos contextuais e sua influência sobre o desenho e os resultados dos processos de participação pública é tão importante quanto escolher o mecanismo de participação adequado.

De acordo com Kegler e colaboradores (2011), há poucos estudos que analisam as características contextuais atreladas a programas durante o processo de implementação. Assim, uma das motivações para esse estudo é colaborar com as ações da Controladoria-Geral da União (CGU), que exerce um relevante papel como fomentador do controle social, no intuito de reduzir as disparidades e estimular a participação da sociedade no Brasil. Entre as diversas ações empenhadas pela CGU que visam especificadamente o fomento ao controle social, podese destacar: i) a Conferência Nacional sobre Transparência e Controle Social (Consocial); ii) o Programa Fortalecimento da Gestão; iii) o Programa Olho Vivo no Dinheiro Público; e, iv) o Projeto Um por Todos e Todos por Um — Pela Ética e Cidadania.

Tendo em vista a importância dessas ações para o fortalecimento da participação no controle da gestão pública no país, torna-se necessário conhecer o contexto municipal, isto é, as características e condições dos espaços de implementação desses programas públicos, no intuito de auxiliar e estimular a atuação da CGU.

Afinal, intervenções que buscam promover a mudança de comportamento não podem ser definidas e avaliadas pelos meios convencionais, uma vez que o processo de implementação e o contexto local têm significativo impacto sobre os resultados que serão obtidos (Bamberger e Segone, 2011).

Entender como o contexto da comunidade pode afetar a capacidade de desenvolvimento de projetos, que buscam criar uma mudança na própria comunidade, auxiliará os profissionais na decisão de se uma abordagem colaborativa é adequada para uma determinada situação e ajudar os financiadores, os prestadores de assistência técnica e os líderes de projeto a antecipar os obstáculos e os problemas antes que eles surjam (Kegler et al., 2011). 
Assim, os domínios contextuais que serão examinados neste trabalho dentro de uma abordagem quantitativa são: demográfico, socioeconômico e político-institucional. A escolha dessas dimensões se deu a partir da literatura científica, como evidenciado no tópico a seguir, que possibilitou compreender quais tipos de variáveis são relevantes, considerando a restrita quantidade de informações disponíveis nos portais governamentais do Brasil que permitem analisar a atuação cidadã no âmbito municipal.

\subsection{Influência do contexto no engajamento cidadão}

As características contextuais auxiliam na compreensão dos diferentes níveis de engajamento dos cidadãos, demonstrando relevância pública por permitirem entender em que situações as pessoas decidem participar (Ulzurrun, 2001). Em sua essência, os estudos sobre a influência contextual concebem o engajamento como uma resposta às condições políticas, econômicas e sociais. Estudiosos da influência contextual e da participação devem estar cientes de quais tipos de aspectos contextuais são importantes para a ação participativa e como esses aspectos interagem com as características de nível individual (Platt, 2012).

Assim, para fortalecer o controle social no estado de Minas Gerais, é necessário compreender quais aspectos contextuais contribuem para o engajamento do cidadão. Nesse sentido, o papel do status socioeconômico e da demografia é enfatizado pela literatura como características que influenciam fortemente na participação. De acordo com Montalvo (2008), as variáveis socioeconômicas e demográficas geram impactos estatisticamente significativos e substancialmente robustos sobre a probabilidade de engajamento cidadão em reuniões municipais.

Sob essa lógica, Brady, Verba e Schlozman (1995) afirmam que os recursos são distribuídos de forma diferente entre os grupos definidos pelo nível socioeconômico, e esses recursos têm efeitos poderosos sobre a atividade política em geral, o que explica por que o status socioeconômico tem sido tradicionalmente tão poderoso na previsão de participação. Há vários recursos que ajudam a explicar a participação política, além de explicações somente com base em um ou mais dos componentes do nível socioeconômico, como educação, renda e ocupação.

Entre os recursos ressaltados por esses autores, têm-se as habilidades cívicas, relevantes para a participação cidadã, adquiridas pelos adultos em atividades vinculadas a organizações não políticas, como as organizações religiosas. As igrejas são mais igualitárias nas oportunidades de habilidades cívicas que proporcionam, e as habilidades ou competências cívicas podem ser medidas de várias maneiras, como, por intermédio da capacidade de organização e comunicação adquirida na escola, no trabalho, nas igrejas. Além disso, esses autores também salientam que há disparidades na atividade participativa entre grupos distinguidos por características demográficas.

Os resultados obtidos por Montalvo (2008) corroboram esse fato ao mostrarem que aqueles indivíduos que participam mais frequentemente de serviços religiosos são mais pro- 
pensos a se envolver em reuniões municipais. Nesse sentido, tem-se Rennó (2003), que alega que, no caso da América Latina, o aparato institucional de cada país, aliado à percepção individual sobre o funcionamento das instituições, é um determinante mais intenso da participação do que as predisposições psicológicas individuais na participação em organizações sociais e políticas.

Vráblíková (2013) argumenta que, além de recursos, motivações e mobilização, as oportunidades institucionais também facilitam a participação individual na política não somente eleitoral, visto que a descentralização das instituições do Estado oferece mais pontos de acesso aos cidadãos para influenciar a política e aumentar as possibilidades de impacto sobre a tomada de decisão. O ativismo cidadão deverá aumentar se as oportunidades de participação nos assuntos públicos estiverem abertas. Por outro lado, se os cidadãos acreditam que as oportunidades para influenciar as decisões públicas estão fechadas, isso irá diminuir o ativismo.

Sobre esse aspecto, Castro (2003) afirma que é por intermédio do arcabouço institucional que se concretiza o exercício da cidadania. A autora alega que, embora a constituição dos conselhos seja uma obrigação legal em todos os níveis da federação, não há um padrão de funcionamento e as distinções podem ser analisadas como indicadores das condições de mobilização e participação da sociedade local.

Já com relação aos aspectos político-institucionais, tem-se Platt Neto e colaboradores (2007), que categorizaram os principais usuários e interessados pelos dados e informações contidos nas contas públicas do Brasil, entre os quais podem-se destacar os contribuintes, empresários, ONGs e associações, partidos políticos, entre outros.

A partir do exposto, pode-se observar a amplitude das características contextuais que influenciam no engajamento cidadão. A relevância desse assunto pode ser vista pela extensão de estudos que analisam a participação da sociedade em diferentes países, tais como: Orueta (2006), que investigou as práticas democráticas de governos locais na Espanha; Lukensmeyer (2007), que analisou os desafios de se considerar o engajamento dos cidadãos em ampla escala após o Katrina em Nova Orleans, nos EUA; Díaz-Cayeros e colaboradores (2014), que estudaram uma forma de democracia participativa prevalente em comunidades indígenas no México; e Barnes (1966), que examinou as relações entre participação, educação e competência política em membros de um partido político na Itália.

Entre os estudos recentes que abrangem o tema participação e o controle social no Brasil, podem-se destacar: Oliveira e Pisa (2015), que buscaram desenvolver um índice de medição da governança pública para as unidades federativas do país; Buvinich (2014), que analisou como estão sendo implantados os conselhos de políticas e programas nos municípios brasileiros; e Almeida, Silva e Pessoa (2013), que buscaram compreender a relação entre a participação em redes transnacionais e a influência desse engajamento na formulação de políticas públicas municipais. Dada a importância desse tema, visando analisar como as características contextuais interagem com a atuação cidadã na realidade de Minas Gerais, apresentam-se a seguir os procedimentos metodológicos empregados para alcançar essa finalidade. 


\section{Metodologia}

O presente estudo apresenta uma abordagem quantitativa com delineamento dos dados em seção cruzada no período de 2010. Quanto aos objetivos, caracteriza-se como uma pesquisa descritiva, uma vez que busca descrever e analisar um conjunto de características do contexto municipal que contribuem para o engajamento cidadão no controle social em Minas Gerais. A seguir são apresentados os procedimentos metodológicos, as variáveis utilizadas, a caracterização da área de estudo, a fonte e a forma de tratamento dos dados.

\subsection{Análise fatorial}

A fim de identificar os fatores que explicam as possíveis diferenças de participação cidadã no exercício do controle da gestão pública em Minas Gerais, o modelo de análise fatorial exploratória foi empregado por ser a técnica de análise multivariada apropriada para essa finalidade, uma vez que será utilizado um considerável número de variáveis.

Em situações em que há número elevado de variáveis mensuradas e correlacionadas entre si, é admissível, por intermédio da análise fatorial, identificar um número menor de novas variáveis alternativas, não correlacionadas e que resumem as informações fundamentais das variáveis originais. As novas variáveis identificadas são denominadas de fatores ou variáveis latentes (Mingoti, 2007). Conforme Lima (2014), o modelo ortogonal da análise fatorial apresenta a seguinte expressão analítica:

$$
X_{p x 1}=\mathrm{A}_{p x r} \cdot \mathrm{F}_{r x 1}+\varepsilon_{p x 1}
$$

em que: $X=$ vetor de variáveis originais; $F=$ vetor de fatores comuns; $A=$ matriz de cargas fatoriais; $\varepsilon=$ vetor de erros aleatórios (fatores específicos mais erro); $r$ (número de fatores) $<p$ (número de variáveis).

Os fatores são estimados mediante uma combinação linear das variáveis originais:

$$
\begin{gathered}
F_{j}=\omega_{j 1} \cdot X_{1}+\omega_{j 2} \cdot X_{2}+\omega_{j 3} \cdot X_{3}+\ldots+\omega_{j i} \cdot X_{i} \\
F_{j}=\sum_{i=1}^{\mathrm{n}} \omega_{j i} \cdot
\end{gathered}
$$

em que $F_{j}$ são os fatores comuns não relacionados, $\omega_{j i}$ são os coeficientes dos escores fatoriais e $X_{i}$ são as variáveis originais envolvidas no estudo. O escore fatorial é um número resultante da multiplicação dos coeficientes $\omega_{j i}$ pelo valor das variáveis originais (Corrar, Paulo e Dias Filho, 2007).

De acordo com Lima (2014), as variáveis quantitativas empregadas no modelo de análise fatorial são contínuas, expressas em unidades diferentes. Para evitar problemas devido às distintas unidades de medidas e a influência que uma variável com grande variância pode ter na determinação das cargas fatoriais, as variáveis foram padronizadas por meio do escore z, dado por: 


$$
x_{i j}=\frac{X_{i j}-\bar{X}_{\mathrm{j}}}{S_{j}}
$$

em que $x_{i j}$ é a nova variável, denominada variável padronizada, $X_{i j}$ é a variável ${ }_{\mathrm{i}}, \bar{X}_{\mathrm{j}}$ é a média e $S_{j}$ é o desvio-padrão.

A padronização resolve o problema de unidades de medidas diferentes das variáveis e do desbalanceamento entre as variâncias e simplifica cálculos e manipulações matemáticas. Ressalta-se que, ao usar a matriz de correlações das variáveis, em vez da matriz de variâncias e covariâncias, tem-se o mesmo resultado que trabalhar com as variáveis padronizadas (Lima, 2014).

O modelo de análise fatorial foi estimado pelo método de componentes principais por não exigir informações ou suposições sobre a distribuição normal multivariada dos dados. Para facilitar a interpretação dos fatores, este estudo utiliza o método Varimax de rotação ortogonal. As variáveis latentes identificadas nesta pesquisa possibilitam determinar as relações quantitativas ao agregar aquelas que apresentam padrão semelhante, indicando os fatores explicativos das diferenças de participação cidadã no controle social. Além disso, os escores fatoriais foram empregados na construção de um índice, como explicado a seguir.

\subsection{Construção do Índice de Potencial para o Controle Social (IPCS)}

Conforme mencionado, inicialmente aplicou-se a análise fatorial para obtenção dos fatores e escores fatoriais que foram utilizados para a construção do IPCS. Para estimação e elaboração do IPCS, foram tomados como referência os procedimentos adotados por Lemos (2001) e Cunha e colaboradores (2008). O IPCS é uma proxy que representa o potencial de participação dos cidadãos no controle social em nível municipal. Esse índice tem como função permitir determinar, por intermédio da hierarquização, os municípios mais ou menos favoráveis à participação.

Para a constituição do IPCS, os fatores foram agregados de acordo com a equação (Cunha et al., 2008):

$$
I P C S_{i}=\sum_{j=1}^{p} \frac{\lambda_{j}}{\Sigma \lambda_{j}} F_{j i}^{*}
$$

em que IPCS é o índice do i-ésimo município, $j$ é a j-ésima raiz característica, $p$ é o número de fatores extraídos na análise, $F_{j i}^{*}$ é o j-ésimo escore fatorial do i-ésimo município e $\Sigma \lambda_{\mathrm{j}}$ é o somatório das raízes características referentes aos $\mathrm{p}$ fatores extraídos. A participação relativa do fator $j$ na explicação da variância total captada pelos $p$ fatores extraídos é indicada por $\frac{\lambda_{j}}{\Sigma \lambda_{j}}$.

No entanto, antes de agregar as variáveis no índice, é necessário transformar todos os escores fatoriais em valores positivos e com variações entre zero e um. Segundo Lemos (2001), 
essa transformação é necessária para evitar que altos escores fatoriais negativos elevem a magnitude dos índices associados a esses municípios. Para isso, procede-se à seguinte transformação:

$$
F i j=\frac{\left(F-F_{\text {min }}\right)}{\left(F_{\text {max }}-F_{\text {min }}\right)}
$$

em que $F_{\min }$ e $F_{\max }$ são os valores máximo e mínimo observados, respectivamente, para os escores fatoriais associados aos municípios mineiros.

\subsection{Variáveis empregadas}

Para identificar os fatores explicativos que colaboram para o engajamento cidadão no controle social em nível municipal, este estudo considerou as expectativas teóricas para selecionar 13 variáveis relacionadas com as condições socioeconômicas, demográficas e político-institucionais, abarcando, assim, as dimensões destacadas na revisão bibliográfica. As variáveis selecionadas são:

$\mathrm{X} 1$ = taxa de pessoas com ensino superior;

$\mathrm{X} 2$ = renda per capita;

X3 = taxa de urbanização;

X4 = proporção do número de usuários de internet fixa em relação à população;

X5 = proporção do número de ONGs em relação à população;

X6 = proporção do número de pessoas ocupadas em relação à população;

X7 = proporção do número de empresas em atividade em relação à população;

X8 = proporção do número de eleitores filiados a partidos políticos em relação à população;

X9 = número de partidos políticos no município;

X10 = proporção do número de membros de entidades religiosas em relação à população;

$\mathrm{X} 11$ = número de conselhos municipais atuantes;

$\mathrm{X} 12$ = número de legislações, normas e regras municipais (LNRM);

$\mathrm{X} 13$ = número de políticas, planos e programas municipais (PPPM).

A variável taxa de pessoas com ensino superior foi empregada por representar um indicador de acesso da população à educação municipal; juntamente com a variável renda per capita, abrange os aspectos socioeconômicos destacados como importantes para o engajamento cidadão. No tocante ao aspecto demográfico, foi selecionada a variável taxa de urbanização, pois se considera que no meio rural as comunicações são mais difíceis e mais 
custosas, podendo haver certo isolamento, o que é um obstáculo para os processos participativos. E considerou-se também a variável proporção de usuários de internet fixa pois, quanto maior o acesso à informação pelos cidadãos, maior é a possibilidade de atuação, seja de forma individual, através de consultas em sites de informação pública, ou por meio de articulações via redes sociais.

Já em relação aos aspectos político-institucionais, foi empregada a variável proporção do número de ONGs, que é dado pelo total de Fundações Privadas e Associações sem Fins Lucrativos (Fasfil), e a variável proporção do número de pessoas ocupadas em relação à população, como proxy de contribuintes. Destaca-se que, nesta variável, não se consideraram as pessoas com vínculos formais na administração pública, pelo fato de que os funcionários públicos são menos propensos a exercer o controle social; pelo contrário, eles estão diretamente sob a incidência desse controle. Além disso, foram utilizadas as variáveis proporção do número de empresas em atividade; proporção do número de eleitores filiados a partidos políticos; número de partidos políticos; e proporção do número de membros de entidades religiosas. As variáveis selecionadas para esse aspecto visam abranger os principais interessados no exercício do controle social no âmbito municipal, isto é, os atores externos.

Por outro lado, a seleção das variáveis número de conselhos municipais atuantes, número de legislações, normas e regras municipais (LNRM) e número de políticas, planos e programas municipais (PPPM) visou englobar o arcabouço institucional presente no municí-

pio. É importante destacar que essas variáveis foram construídas a partir de dados brutos da Fundação João Pinheiro (FJP) e do Instituto Brasileiro de Geografia e Estatística (IBGE).

\section{4 Área de estudo, fonte e tratamento dos dados}

Este estudo adota como amostra os 853 municípios de Minas Gerais, com vistas a viabilizar uma análise de escopo estadual. Para compor o conjunto de dados secundários que possibilitaram realizar as análises, serviram como base de coleta: a) Índice Mineiro de Responsabilidade Social (IMRS), da Fundação João Pinheiro (FJP); b) Instituto Brasileiro de Geografia e Estatística (IBGE); c) Relação Anual de Informações Sociais (Rais), do Ministério do Trabalho; d) Atlas do Desenvolvimento Humano no Brasil, do Programa das Nações Unidas para o Desenvolvimento no Brasil (PNUD); e) Ministério das Comunicações; e f) Tribunal Superior Eleitoral (TSE). Objetivando o tratamento e a análise dos dados coletados, utilizou-se a planilha eletrônica Excel e o software Statistical Package for Social Sciences (SPSS).

\section{Apresentação e discussão dos resultados}

\subsection{Condições municipais para o engajamento cidadão}

O modelo de análise fatorial está fundamentado em suposições que não podem ser verificadas a priori, como a linearidade e independência entre os fatores. Por isso, é necessário avaliar até 
que ponto a matriz de cargas fatoriais estimada representa adequadamente a relação entre as variáveis originais e os fatores do modelo (Mingoti, 2007).

Assim, a forma de validação empregada neste estudo, considerando o grande número de observações, foi a divisão aleatória do conjunto de dados em duas partes; foram realizados os procedimentos em ambas as partes, atendendo à indicação de Mingoti (2007). O procedimento adotado demonstrou consistência nas soluções encontradas, em comparação com o conjunto total de dados. A fim de atender à premissa de baixa multicolinearidade, foram realizados procedimentos que indicaram reduzido grau de multicolinearidade entre as variáveis.

O número de casos utilizados é 853 , e o número de variáveis empregadas é 13 , o que indica que o critério de 10 observações para cada variável envolvida foi abrangido sem maiores problemas, atendendo ao critério salientado por Lima (2014). Dessa maneira, o estudo buscou respeitar os pressupostos gerais do modelo de análise fatorial.

Dada essa explicação inicial, é possível apresentar os resultados obtidos com a aplicação do modelo. Em relação ao padrão de correlação entre as variáveis, a matriz de correlações exibiu a maior parte dos coeficientes com valor acima de 0,3 . Apenas três variáveis (proporção do número de ONGs, proporção de membros de entidade religiosa e proporção do número de eleitores filiados a partidos políticos) apresentaram coeficientes pouco inferiores ao recomendado. Contudo, optou-se por manter essas variáveis por considerá-las importantes na literatura.

Os testes de adequação da amostra se apresentaram satisfatórios. O teste de esfericidade de Bartlett foi significante a menos que 1\%, ou seja, rejeita-se a hipótese nula de que a matriz de correlações é igual a uma matriz identidade. Já o critério KMO apresentou resultado de 0,883 , superior ao patamar crítico de 0,6 , o que, conforme a literatura, é uma ótima medida de adequabilidade dos dados.

A aplicação da análise fatorial com decomposição em componentes principais resultou na extração de três fatores, considerando o critério de Kaiser, de raízes características $(\lambda)$ maiores que 1 , como pode ser verificado na tabela 1 .

Tabela 1

Número de fatores e porcentagem de explicação da variância

\begin{tabular}{|cccc|}
\hline Fator & Raiz Característica $\lambda_{i}$ & Inicial (\%) & Rotativa (\%) \\
\hline 1 & 4,040 & 40,397 & 31,073 \\
2 & 2,584 & 10,945 & 19,877 \\
3 & 1,205 & 8,881 & 9,273 \\
Total & - & 60,223 & 60,223 \\
\hline
\end{tabular}

Fonte: Resultados da pesquisa.

Os fatores, após a rotação ortogonal Varimax, apresentaram, respectivamente, uma explicação de $31,07 \%, 19,88 \%$ e 9,27\% da variância; em conjunto, esses três fatores explicam $60,22 \%$ da variância das variáveis originais. Na tabela 2 são apresentados os resultados das cargas fatoriais rotacionadas e das comunalidades. 
As comunalidades representam a proporção da variância para cada variável estudada, que é explicada pelos três fatores extraídos, ou seja, as comunalidades indicam as variáveis consideradas mais representativas na construção dos componentes. No caso deste estudo, as variáveis mais representativas foram a taxa de pessoas com ensino superior e a proporção de empresas - duas variáveis fortemente mencionadas na literatura sobre participação, devido à sua relevância.

De acordo com Barnes (1966), a educação formal é um meio para se adquirir tanto conhecimento substantivo quanto sentimento de eficácia política, que são essenciais para o comportamento político, e as pessoas mais estudadas possuem reconhecidamente as maiores taxas de participação. Já Yang e Callahan (2007) salientam que as comunidades em que os representantes empresariais são mais participativos pressionam o governo local, tornando esses locais susceptíveis para haver maior esforço do poder público em envolver diferentes atores externos no processo de tomada de decisões estratégicas.

Geralmente, o valor mínimo aceitável para a comunalidade é de 0,50. Em uma perspectiva conservadora, as variáveis número de conselhos atuantes, número de PPPM e proporção de membros de entidades religiosas deveriam ser excluídas, e deveria ser efetuada a análise fatorial novamente. Entretanto, em razão da importância dessas variáveis, considerou-se necessário conservá-las no estudo.

Tabela 2

Cargas fatoriais rotacionadas e comunalidades

\begin{tabular}{|c|c|c|c|c|}
\hline \multirow{2}{*}{ Variáveis } & \multicolumn{3}{|c|}{ Cargas Fatoriais } & \multirow{2}{*}{ Comunalidades } \\
\hline & $\mathrm{F} 1$ & F2 & F3 & \\
\hline Renda per capita & 0,896 & 0,166 & $-0,039$ & 0,627 \\
\hline Prop. de Empresas & 0,784 & 0,048 & 0,250 & 0,725 \\
\hline Tx. Pessoas Ensino Superior & 0,762 & 0,374 & 0,066 & 0,833 \\
\hline Prop. de Pessoas Ocupadas & 0,755 & 0,252 & $-0,110$ & 0,646 \\
\hline Taxa Urbanização & 0,734 & 0,224 & $-0,195$ & 0,680 \\
\hline Prop. Usuários Internet Fixa & 0,707 & 0,195 & $-0,091$ & 0,546 \\
\hline № de Conselhos Atuantes & 0,352 & 0,686 & 0,016 & 0,454 \\
\hline Prop. Eleitos Filiados a Partidos & 0,068 & $-0,671$ & 0,047 & 0,647 \\
\hline № de Partidos Políticos & 0,327 & 0,671 & $-0,186$ & 0,595 \\
\hline № de LNRM & 0,374 & 0,664 & 0,065 & 0,591 \\
\hline № de PPPM & 0,207 & 0,633 & $-0,020$ & 0,457 \\
\hline Prop. de ONGs & 0,054 & 0,116 & 0,794 & 0,585 \\
\hline Prop. Membros Ent. Religiosas & $-0,104$ & $-0,192$ & 0,637 & 0,443 \\
\hline
\end{tabular}

Fonte: Resultados da pesquisa. 
Além das comunalidades, devem ser analisadas também as cargas fatoriais de cada variável em relação aos componentes extraídos. É possível notar que foi atendido o critério de que uma mesma variável não deve contribuir acima de 0,4 para a construção dos três fatores. Esse limite é indicado para evitar problema de indeterminação da relação entre variáveis e fatores. Em razão disso, foi possível identificar sem maiores dificuldades quais variáveis se relacionam com quais fatores, como pode ser visto em destaque na tabela 2.

Uma vez que um dos propósitos deste estudo é conhecer os fatores que proporcionam condições favoráveis para o exercício do controle social, procurou-se discutir cada um dos fatores que foram retidos, considerando o padrão de relacionamento identificado e a literatura consultada:

- Fator 1 = Estrutura Municipal: é referente aos aspectos do município sobre os quais o cidadão não tem necessariamente influência, mas que interferem diretamente sobre a sua participação, como acesso à educação, desenvolvimento econômico e distanciamento espacial entre os atores (área rural $\times$ área urbana).

- Fator 2 = Contexto Institucional: é relativo ao arcabouço institucional presente no município. Quanto maior a presença institucional, maior será a capacidade dos cidadãos de controle e monitoramento das ações públicas, pois pressionam as organizações públicas a se tornarem mais eficientes, transparentes e socialmente responsáveis pelos seus resultados.

、 Fator 3 = Mobilização Social: refere-se aos aspectos de participação do cidadão na sociedade, uma vez que as privações do contexto municipal movem seus habitantes a cooperarem na busca de melhores condições para a coletividade. A mobilização de membros de entidades religiosas em organizações não governamentais (ONGs) é estimulada para pressionar a administração pública municipal por melhores resultados. As relações interpessoais no âmbito comunitário são fundamentais para o fortalecimento do engajamento cidadão nos municípios e, consequentemente, para o exercício do controle social.

Tendo como base o aporte teórico de Inglehart e Welzel (2010) e de Welzel, Inglehart e Klingemann (2003), pode-se esboçar uma possível interação entre os três fatores encontrados nesse estudo: municípios com elevados níveis de Estrutura Municipal apresentam cidadãos com maior disponibilidade de recursos individuais, o que fortalece a Mobilização Social, além de beneficiar o Contexto Institucional, ou seja, o florescimento das instituições democráticas.

Além de identificar e interpretar os fatores, com a obtenção dos escores fatoriais, foi possível mensurar o quanto os municípios favorecem a participação dos cidadãos na administração pública em Minas Gerais, mediante o estabelecimento do Índice de Potencial para o Controle Social (IPCS), como pode ser visto na figura 1. 
Figura 1

Estrutura que compõe o IPCS

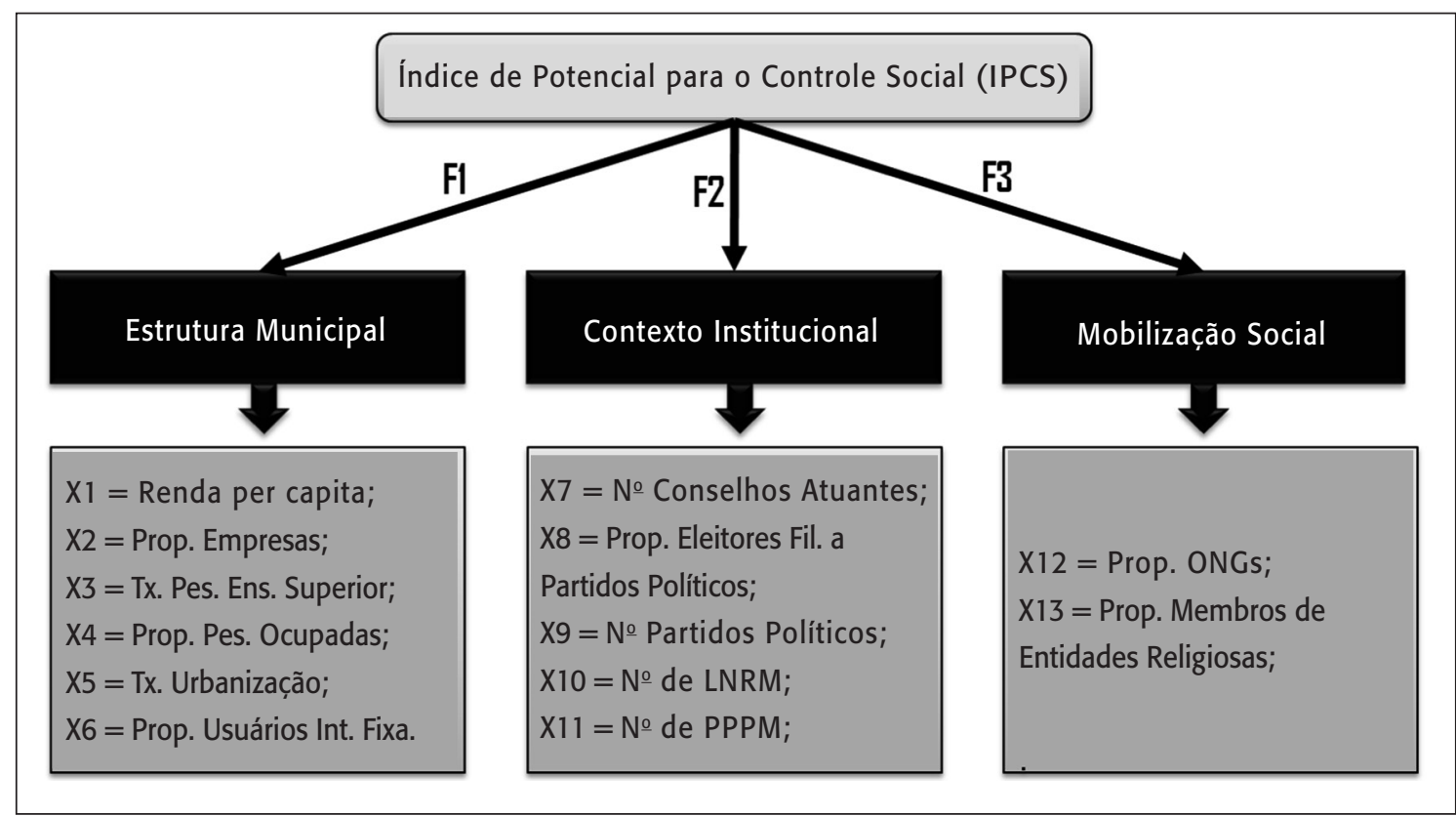

Fonte: Elaborada pelos autores.

Nessa lógica, a figura 1 buscou evidenciar quais variáveis se relacionam com qual fator, no intuito de ilustrar a razão da nomeação dada aos fatores e sua respectiva interpretação. A seguir, são apresentados os resultados obtidos com o IPCS.

\section{2 Índice de Potencial para o Controle Social (IPCS)}

Com a finalidade de hierarquizar os municípios em termos de ambientes favoráveis à participação, foi estabelecido o IPCS. Ao considerar conjuntamente os fatores Estrutura Municipal, Contexto Institucional e Mobilização Social em um índice, foi possível classificar os municípios do estado de Minas Gerais, revelando aqueles que são mais ou menos propícios ao envolvimento do cidadão.

O índice calculado mediante os fatores é uma proxy, que representa as condições dos municípios para o engajamento cidadão no controle social. Nessa ótica, torna-se importante mostrar a estatística descritiva do IPCS no estado; para facilitar a interpretação dos dados, o índice foi reparametrizado a partir do maior valor. A amplitude dos dados demonstra as disparidades existentes quanto aos níveis potenciais de exercício do controle social no âmbito municipal. O município com menor potencial para atuação cidadã apresenta o valor de 28,85\%, sendo a diferença deste para o de maior potencial de 71,15\%. 
Tabela 3

Análise descritiva do IPCS (\%) em Minas Gerais

\begin{tabular}{|lccccccccc|}
\hline & Amplitude & Mínimo & Máximo & Média & Mediana & $\begin{array}{c}\text { Desvio- } \\
\text { padrão }\end{array}$ & Variância & Assimetria & Curtose \\
\hline IPCS & 71,15 & 28,85 & 100,00 & 48,39 & 46,57 & 10,18 & 103,661 & 1,063 & 1,370 \\
\hline
\end{tabular}

Fonte: Resultados da pesquisa.

Por outro lado, é interessante ressaltar que a média do estado é pouco superior ao mínimo encontrado - uma diferença de apenas 19,54 pontos percentuais. Já a diferença entre a média e o limite superior é de 51,61 pontos percentuais. O coeficiente de curtose demonstra que a distribuição é considerada leptocúrtica por ser alongada em relação à distribuição normal. Em relação à assimetria, pode-se perceber que a variável apresenta forte assimetria positiva ou à direita.

Tendo em vista as informações obtidas com a análise descritiva do IPCS, procedeu-se a três diferentes testes de normalidade (Jarque-Bera, Kolmogorov-Smirnov e Shapiro-Wilk), os quais indicaram que o índice não possui distribuição normal. Por isso, para facilitar a compreensão dos diferentes patamares do grau potencial de atuação no controle social, dividiu-se o índice em quatro estratos a partir dos quartis. A tabela 4 mostra o nível de cada um dos estratos analisados. Também estão demonstradas as médias da densidade populacional e de todas as 13 variáveis empregadas nesta pesquisa.

Depreende-se que uma parcela consideravelmente grande (75\% do total ou 640 municípios mineiros) apresenta níveis de potencial para atuação cidadã abaixo de 53,39\%. Apenas 30,51\% dos municípios do grupo 4, de maior potencial de atuação, apresentam valores acima de $65 \%$, isto é, somente $7,62 \%$ dos municípios do estado possuem níveis superiores a $65 \%$.

Tabela 4

Caracterização dos estratos do IPCS em Minas Gerais

\begin{tabular}{|c|c|c|c|c|}
\hline Variáveis & Grupo 1 & Grupo 2 & Grupo 3 & Grupo 4 \\
\hline Níveis do IPCS & $0 \%-40,95 \%$ & $40,96 \%-46,57 \%$ & $46,58 \%-53,39 \%$ & $53,40 \% \quad 100 \%$ \\
\hline № de Municípios & 213 & 214 & 213 & 213 \\
\hline Densidade Populacional & 23,48 & 26,38 & 59,14 & 153,86 \\
\hline Taxa de Urbanização & 50,41 & 63,70 & 71,92 & 85,65 \\
\hline Tx. Pes. Ensino Superior & 3,87 & 4,77 & 5,77 & 8,70 \\
\hline Renda per capita & 404,82 & 481,85 & 555,19 & 709,33 \\
\hline Prop. Pessoas Ocupadas & 291,93 & 600,18 & 1055,69 & 1795,93 \\
\hline Prop. de Empresas & 146,71 & 198,72 & 249,21 & 339,27 \\
\hline Prop. Us. Internet Fixa & 130,47 & 184,53 & 326,40 & 695,87 \\
\hline Prop. M. Ent. Religiosas & 9557,13 & 9549,02 & 9572,31 & 9461,71 \\
\hline Prop. ONGs & 14,04 & 20,44 & 22,79 & 22,50 \\
\hline № Conselhos Atuantes & 6,13 & 7,13 & 7,65 & 10,13 \\
\hline
\end{tabular}




\begin{tabular}{|lcccc|}
\hline \multicolumn{1}{c}{ Variáveis } & Grupo 1 & Grupo 2 & Grupo 3 & Grupo 4 \\
\hline № de Partidos Políticos & 12,70 & 13,52 & 14,84 & 19,69 \\
Prop. Eleitores Fil. Part. & 1397,88 & 1375,13 & 1181,35 & 933,74 \\
№ de LNRM & 12,25 & 14,07 & 16,31 & 19,70 \\
№ de PPPM & 5,63 & 6,18 & 6,69 & 8,52 \\
\hline
\end{tabular}

Fonte: Resultados da pesquisa.

Em uma breve descrição, observa-se que, de modo geral, as variáveis apresentaram resultados crescentes do grupo 1 ao grupo 4, podendo-se denominar o grupo 1 de baixo potencial; o grupo 2, de médio; o grupo 3, de regular; e o quarto grupo, de alto potencial para a atuação cidadã. Torna-se necessário destacar o contraste entre os grupos 1 e 2, e o grupo 4, sendo os dois primeiros formados basicamente por cidades de pequeno porte, e o último, formado em sua maior parte (cerca de 61,50\%) por cidades com maior nível de desenvolvimento. No grupo 3 situam-se municípios de todos os tipos. A fim de identificar a distribuição espacial do IPCS, foi elaborado um mapa (figura 2) de acordo com os quatro estratos analisados. O mapa permite melhor visualização dos municípios em suas mesorregiões, segundo seu grau potencial de atuação no controle social.

Figura 2

Mapa do IPCS dos 853 municípios de Minas Gerais por mesorregião

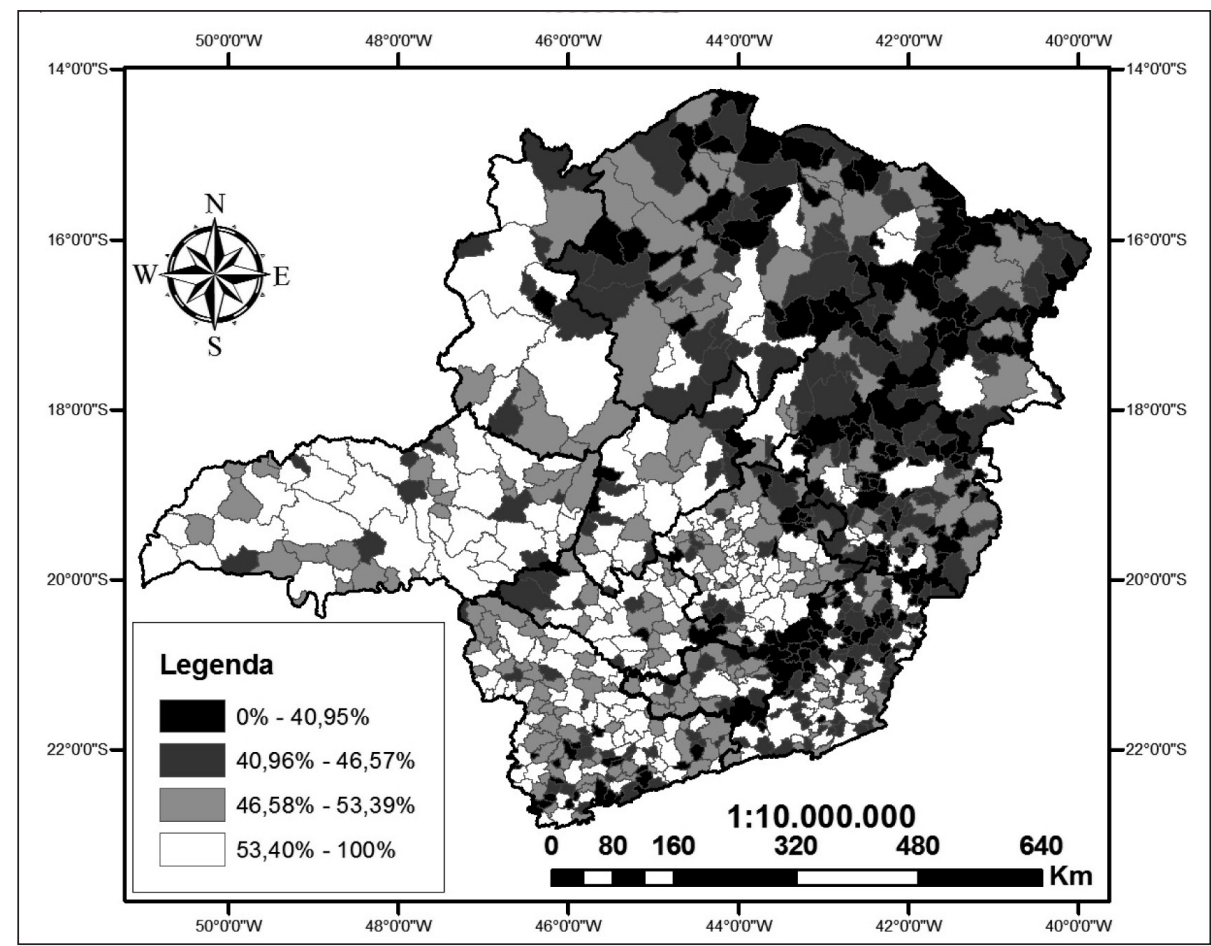

Fonte: Elaborada pelos autores. 
Por intermédio da tabela 5, é possível detectar as diferenças entre as regiões. As mesorregiões, em ordem de importância, com maior concentração de municípios menos favoráveis à participação são Vale do Mucuri, Vale do Rio Doce, Jequitinhonha, Norte de Minas e Zona da Mata, totalizando 5 das 12 regiões. O Triângulo Mineiro/Alto Paranaíba não teve nenhum município no estrato 1, e, em conjunto com o Oeste de Minas, o Noroeste de Minas e a Central Mineira, formam as mesorregiões com menor concentração de municípios de baixo potencial para a participação no controle social.

Todas as mesorregiões estão intensamente presentes nos grupos 2 e 3, de médio e regular potencial. Já no grupo 4, estrato com as condições mais favoráveis à participação, tem-se, em ordem de importância: Triângulo Mineiro/Alto Paranaíba, Oeste de Minas, Metropolitana de Belo Horizonte, Central Mineira, Sul/Sudoeste de Minas e Noroeste de Minas. As mesorregiões com as piores representações neste estrato foram Jequitinhonha, Vale do Rio Doce, Norte de Minas, Vale do Mucuri, Campo das Vertentes e Zona da Mata.

Tabela 5

Dados descritivos do IPCS por mesorregião

\begin{tabular}{|lcccccccc|}
\hline \multicolumn{1}{c}{$\begin{array}{c}\text { Mesorregiões de MG } \\
\text { (Total de Municípios) }\end{array}$} & $\begin{array}{c}\text { G1 } \\
(\%)\end{array}$ & $\begin{array}{c}\text { G2 } \\
(\%)\end{array}$ & $\begin{array}{c}\text { G3 } \\
(\%)\end{array}$ & $\begin{array}{c}\text { G4 } \\
(\%)\end{array}$ & Média & $\begin{array}{c}\text { Desvio- } \\
\text { Padrão }\end{array}$ & Mín. & Máx. \\
\hline Campo das Vertentes (36) & 19,44 & 19,44 & 44,44 & 16,67 & 49,17 & 10,67 & 33,96 & 81,51 \\
Central Mineira (30) & 10,00 & 33,33 & 20,00 & 36,67 & 50,72 & 8,04 & 38,87 & 64,31 \\
Jequitinhonha (51) & 39,22 & 39,22 & 19,61 & 1,96 & 42,85 & 5,65 & 31,51 & 64,62 \\
Metropolitana de Belo Horizonte (105) & 19,05 & 15,24 & 26,67 & 39,05 & 52,04 & 12,14 & 32,64 & 100 \\
Noroeste de Minas (19) & 5,26 & 31,58 & 31,58 & 31,58 & 51,36 & 8,64 & 40,83 & 69,9 \\
Norte de Minas (89) & 34,83 & 35,96 & 21,35 & 7,87 & 44,3 & 7,07 & 32,33 & 72,61 \\
Oeste de Minas (44) & 4,55 & 15,91 & 38,64 & 40,91 & 53,06 & 9,18 & 33,38 & 75,5 \\
Sul/Sudoeste de Minas (146) & 15,75 & 13,01 & 35,62 & 35,62 & 51,77 & 9,83 & 32,5 & 80,19 \\
Triângulo Mineiro/Alto Paranaíba (66) & 0,00 & 13,64 & 36,36 & 50,00 & 55,3 & 9,05 & 42,53 & 83,41 \\
Vale do Mucuri (23) & 47,83 & 30,43 & 13,04 & 8,70 & 42,39 & 7,99 & 30,93 & 64,5 \\
Vale do Rio Doce (102) & 46,08 & 32,35 & 13,73 & 7,84 & 42,88 & 8,08 & 28,85 & 73,01 \\
Zona da Mata (142) & 33,80 & 33,80 & 12,68 & 19,72 & 45,97 & 9,78 & 30,84 & 86,38 \\
\hline
\end{tabular}

Fonte: Resultados da pesquisa.

Diamantina é o único município da mesorregião do Jequitinhonha no grupo de alto potencial. Esse município apresenta resultados acima da média para todos os três escores fatoriais analisados neste estudo, sendo os valores dos fatores Estrutura Municipal e Contexto Institucional consideravelmente elevados, especialmente pelo fato de que a região do Jequitinhonha possui média inferior à do estado quando se trata do fator Estrutura Municipal. Cabe destacar também que Diamantina é o município de maior porte dessa mesorregião. 
Já Teófilo Otoni e Nanuque são, em ordem de importância, os dois municípios do Vale do Mucuri que ficaram alocados no grupo 4, de alto potencial. Esses municípios também são os de maior porte de sua mesorregião. Ambos tiveram valores superiores à média do estado nos fatores 1 e 2, porém obtiveram resultados pouco inferiores aos da média no quesito Mobilização Social.

Por outro lado, Dom Bosco foi o único município do Noroeste de Minas no grupo 1, de baixo potencial, tendo o escore do fator 3, Mobilização Social, o único com resultado superior à média do estado. Camacho e Tapiraí foram os dois municípios do Oeste de Minas que também ficaram alocados no grupo 1. Camacho, assim como Dom Bosco, mostrou escores inferiores à média do estado no fatores 1 e 2, e pouco superior somente no fator 3 . Tapiraí, apesar de ser um dos menores municípios de Minas Gerais (16º no ranking), possui média um pouco superior no quesito Estrutura Municipal, mas mostrou médias inferiores nos fatores $2 \mathrm{e}$ 3. Salienta-se ainda que tanto Dom Bosco quanto Camacho são municípios de pequeno porte.

Contrariamente, o município de Tiradentes, da mesorregião Campo das Vertentes, embora sendo de pequeno porte, possuindo somente 6.961 habitantes, apresentou elevado resultado do IPCS $(67,67 \%)$, estando no restrito grupo de municípios com potencial acima de $65 \%$ para a atuação cidadã. Tiradentes tem valores superiores aos da média do estado nos fatores Estrutura Municipal e Mobilização Social, ficando aquém somente no fator Contexto Institucional.

Nesse sentido, os programas federais que visam incentivar o controle social no Brasil devem dar maior atenção aos municípios e às mesorregiões em situações menos favoráveis, procurando fortalecer ações para a formação de contextos adequados, que beneficiem o engajamento dos cidadãos. Conforme James e Moseley (2014), o baixo desempenho do setor público não necessariamente desencadeia protestos, pois o que ocorre muitas vezes é a falta de voz dos cidadãos, devido ao ceticismo de que a voz coletiva não vai alterar a forma de gestão municipal.

Hiskey e Bowler (2005) compartilham dessa visão ao afirmarem que o contexto local afeta as avaliações da legitimidade do sistema, e essas avaliações, por sua vez, ajudam a moldar a vontade dos cidadãos de se envolver com o sistema político. Os cidadãos estão mais dispostos a participar se eles acham que o processo é justo, e a evidência direta da equidade do sistema é fornecida pelo contexto local.

Já em relação às diferenças dentro de cada mesorregião, a região Metropolitana de Belo Horizonte possui a maior dispersão em torno dos dados, indicando que há grandes diferenças entre os municípios, com escores variando de 32,64 a 100,00 - uma diferença de 67,36 pontos percentuais. Belo Horizonte é o município de Minas Gerais com as condições mais favoráveis para o engajamento cidadão. Esse fato corrobora os resultados encontrados no estudo de Ferreira, Silva e Oliveira (2014), os quais afirmam que alguns mecanismos de engajamento, como audiências públicas de monitoramento de programas públicos, somente são efetuados na capital do estado, restringindo a participação dos cidadãos mineiros nesses processos.

As outras mesorregiões que mostraram maior diversidade na sequência foram Campo das Vertentes, Sul/Sudoeste de Minas, Zona da Mata, Oeste de Minas e Triângulo Mineiro/ 
Alto Paranaíba. Já Jequitinhonha, Norte de Minas, Vale do Mucuri e Central Mineira apresentaram menor variabilidade, devido aos baixos valores do desvio-padrão apresentados por essas mesorregiões. Entretanto, a baixa variação de Jequitinhonha e Norte de Minas deve-se ao fato de a maior parte de seus municípios estar concentrada entre os grupos 1 e 2, de baixo e médio potencial, ao passo que os municípios da Central Mineira estão concentrados mais fortemente entre os grupos 2, 3 e 4, de médio a alto potencial para o controle social.

Devido aos resultados obtidos nesse estudo, convém reforçar que, em sociedades pobres nas quais dominam valores de conformidade, a maioria dos residentes não tem nem recursos e nem a motivação necessária para formar um engajamento cidadão efetivo de tal modo que seus governantes se sintam pressionados a respeitar os direitos da população (Welzel, Inglehart e Klingemann, 2003). Em contrapartida, o desenvolvimento socioeconômico tende a trazer mudanças sociais e culturais de longo prazo que elevam a confiança, a tolerância, o ativismo político, o apoio a igualdade de gênero, e a ênfase na liberdade de expressão, propiciando assim a sociedade civil, a participação dos cidadãos e a democracia (Inglehart e Welzel, 2010).

Nesse sentido, Buvinich (2014) afirma que existe a necessidade de se prosseguir no desenvolvimento da adequação dos modelos de participação brasileiros em razão de características próprias do contexto de cada região, para que esses mecanismos possam gerar resultados cada vez mais justos, eficientes e redistributivos, que colaborem para a edificação de uma sociedade mais equitativa.

Portanto, pode-se afirmar que o estado de Minas Gerais apresenta significantes desigualdades quando se trata de oferecer condições favoráveis à atuação cidadã no controle social. Em geral, os municípios que melhor se apresentaram em relação ao IPCS são também aqueles que demonstraram maior nível de desenvolvimento, o que avigora a necessidade de se empenhar em políticas de desenvolvimento local e regional.

\section{Considerações finais}

Este estudo construiu um índice que buscou representar o potencial de inclusão democrática dos municípios via controle social. A análise do contexto dos municípios mineiros no que se refere às condições proporcionadas para viabilizar a participação no controle social, numa abordagem quantitativa, raramente visualizada nos estudos sobre o tema, amplia o foco dos trabalhos realizados no país, evidenciando novas alternativas.

Os resultados indicaram consideráveis disparidades em relação ao potencial que os municípios mineiros têm para favorecer o engajamento cidadão no controle social. Isso sugere a necessidade de se trabalhar nos fatores Estrutura Municipal, Contexto Institucional e Mobilização Social, identificados no estudo, visando elevar a possibilidade de participação da sociedade no controle da gestão pública.

As desigualdades entre os municípios de Minas Gerais apontam a necessidade de se elaborar um sistema de gestão de desempenho direcionado para a questão do engajamento 
no controle social, a partir da coleta e disponibilização sistemática de informações, que possibilite realizar o acompanhamento da evolução da participação cidadã e, concomitantemente, da melhora na aplicação dos gastos públicos.

Ademais, pode-se concluir que programas existentes do governo federal, que buscam fortalecer o exercício da participação no controle social, como os coordenados pela CGU, devem ser aprimorados no sentido de ampliar as suas ações no âmbito municipal. Assim, com base nas relações apresentadas ao longo do estudo, torna-se factível estabelecer prioridades no sentido de apoiar os municípios que se encontram em situações menos favoráveis, a fim de que seus cidadãos possam ser efetivamente envolvidos, no intuito de buscar soluções adequadas para a melhoria do local em que residem.

Entre as limitações deste estudo, pode-se ressaltar a carência de dados e informações, em termos de qualidade e abrangência, o que dificulta a expansão das pesquisas quantitativas nesse tema, além da escassa literatura nacional que utiliza esse tipo de abordagem. Sugere-se que estudos posteriores busquem aprofundar o conhecimento da realidade do estado, a partir de estudos comparativos, com abordagem qualitativa nos casos extremos, de municípios benchmark e anti-benchmarck na relação de potencial para o engajamento no controle social. Além disso, recomenda-se compreender a realidade de outros estados, visando ampliar o conhecimento desse assunto no contexto nacional.

Haja vista, a extensa diversidade brasileira, é interessante também que seja analisado o contexto municipal por intermédio de outras dimensões não contempladas neste estudo, tais como: histórica, administrativa, cultural, entre outras. Afinal, ao se aprofundar no conhecimento sobre as características contextuais dos municípios que influem no engajamento dos cidadãos, será possível direcionar com mais efetividade os planos e projetos que são concebidos, considerando as diferentes realidades do Brasil.

\section{Referências}

ABELSON, Julia et al. Examining the role of context in the implementation of a deliberative public participation experiment: results from a Canadian comparative study. Social Science \& Medicine, v. 64, n. 10, p. 2115-2128, 2007.

ALMEIDA, Lia de A.; SILVA, Mônica Aparecida da R.; PESSOA, Ronaldo Augusto C. Participação em redes transnacionais e a formulação de políticas locais em mudanças climáticas: o caso de Palmas. Rev. Adm. Pública, v. 47, n. 6, p. 1429-1449, nov./dez. 2013.

BAMBERGER, Michael; SEGONE, Marco. How to design and manage equity-focused evaluations. Nova York: Unicef, 2011.

BARNES, Samuel H. Participation, education, and political competence: evidence from a sample of Italian socialists. The American Political Science Review, v. 60, n. 2, p. 348-353, jun. 1966. 
BRADY, Henry E.; VERBA, Sidney; SCHLOZMAN, Kay L. Beyond Ses: a resource model of political participation. The American Political Science Review, v. 89, n. 2, p. 271-294, jun. 1995.

BUVINICH, Danitza P. R. O mapeamento da institucionalização dos conselhos gestores de políticas públicas nos municípios brasileiros. Rev. Adm. Pública, v. 48, n. 1, p. 55-82, jan./fev. 2014.

CASTRO, Iná E. de. Instituições e território: possibilidades e limites ao exercício da cidadania. Geosul, v. 18, n. 36, p. 7-28, jul./dez. 2003.

CORRAR, Luiz J.; PAULO, Edilson; DIAS FILHO, José Maria. Análise multivariada para os cursos de administração, ciências contábeis e economia. São Paulo: Atlas, 2007.

COSTA, Caio César de M. et al. Disparidades inter-regionais e características dos municípios do Estado de Minas Gerais. Desenvolvimento em Questão, v. 10, n. 20, p. 52-88, maio/ago. 2012.

CUNHA, Nina Rosa da S. et al. A intensidade da exploração agropecuária como indicador da degradação ambiental na região dos cerrados, Brasil. Revista de Economia Rural, v. 46, n. 2, p. 291-323, abr./jun. 2008.

DÍAZ-CAYEROS, Alberto; MAGALONI, Beatriz; RUIZ-EULER, Alexander. Traditional governance, citizen engagement, and local public goods: evidence from Mexico. World Development, v. 53, p. 80-93, jan. 2014.

FERREIRA, Marco A. M.; SILVA, Ambrozina A. P.; OLIVEIRA, Anderson. Monitoreo de políticas públicas en Brasil: ¿̇nstrumento de promoción de la transparencia y del accountability u objeto normativo? Circunstancia, v. 12, n. 35, sep. 2014.

FILIPPIM, Eliane S.; ROSSETTO, Adriana M.; ROSSETTO, Carlos Ricardo. Abordagens da administração pública e sua relação com o desenvolvimento em um contexto regional: o caso do Meio Oeste Catarinense. Cad. EBAPE.BR, v. 8, n. 4, p. 734-752, jan./dez. 2010.

HISKEY, Jonathan T.; BOWLER, Shaun. Local context and democratization in Mexico. American Journal of Political Science, v. 49, n. 1, p. 57-71, jan. 2005.

INGLEHART, Ronald; WELZEL, Christian. Changing mass priorities: the link between modernization and democracy. Perspectives on Politics, v. 8, n. 2, p. 551-567, jun. 2010.

JAMES, Oliver; MOSELEY, Alice. Does performance information about public services affect citizens' perceptions, satisfaction, and voice behaviour? Field experiments with absolute and relative performance information. Public Administration, v. 92, n. 2, p. 493-511, jun. 2014.

KEGLER, Michelle C.; RIGLER, Jessica; HONEYCUTT, Sally. The role of community context in planning and implementing community-based health promotion projects. Evaluation and Program Planning Journal, v. 34, n. 3, p. 246-253, 2011.

KLERING, Luis R.; SCHRÖEDER, Christine da S. Políticas e estratégias públicas municipais: novos desafios e perspectivas para o desenvolvimento local. Revista do Desenvolvimento Regional, v. 13, n. 2, p. 144-160, maio/ago. 2008.

LEMOS, José de J. S. Níveis de degradação no Nordeste brasileiro. Revista Econômica do Nordeste, v. 32, n. 3, p. 406-429, jul./set. 2001. 
LIMA, João E. de. Curso de análise estatística multivariada. Viçosa, MG: Universidade Federal de Viçosa/Centro de Ciências Agrárias/Departamento de Economia Rural, 2014.

LUKENSMEYER, Carolyn J. Large-scale citizen engagement and the rebuilding of New Orleans: a case study. National Civic Review, v. 96, n. 3, p. 3-15, 2007.

MINGOTI, Sueli Aparecida. Análise de dados através de métodos de estatística multivariada: uma abordagem aplicada. Belo Horizonte: Editora UFMG, 2007.

MONTALVO, Daniel. Participación ciudadana en sesiones municipales. Revista de Ciencia Política, v. 28, n. 3, p. 219-228, 2008.

OLIVEIRA, Antonio G. de; PISA, Beatriz J. IGovP: índice de avaliação da governança pública instrumento de planejamento do Estado e de controle social pelo cidadão. Rev. Adm. Pública, v. 49, n. 5, p. 1263-1290, set./out. 2015.

ORUETA, Fernando D. Spain: local democracy and citizen participation. Space and Polity, v. 10, n. 3, p. 263-278, dez. 2006.

PLATT, Matthew B. Boons, banes, and neutrals: context and disparities in political participation. Cambridge, Mass.: Harvard University, Departament of Government, 2012.

PLATT NETO, Orion Augusto et al. Publicidade e transparência das contas públicas: obrigatoriedade e abrangência desses princípios na administração pública brasileira. Contabilidade Vista \& Revista, v. 18, n. 1, p. 75-94, jan./ mar. 2007.

RENNÓ, Lucio. R. Estruturas de oportunidade política e engajamento em organizações da sociedade civil: um estudo comparado sobre a América Latina. Revista de Sociologia Política, n. 21, p. 71-82, nov. 2003.

ROGERS, Patricia; HUMMELBRUNNER, Richard. Methodological challenges in using programme theory to evaluate pro-poor and equity-focused programmes. In: SEGONE, Marco. Evaluation for equitable development results. Nova York: Unicef, 2012. p. 142-171.

SERRA, Rita de Cássia C.; CARNEIRO, Ricardo. Controle social e suas interfaces com os controles interno e externo no Brasil contemporâneo. Espacios Públicos, v. 15, n. 34, p. 43-64, maio/agosto 2012.

SHEEDY, Amanda. Handbook on citizen engagement: beyond consultation. Ottawa: Canadian Policy Research Networks, 2008.

ULZURRUN, Laura M. Diez de. Citizens in polities: the individual and contextual determinants of political membership in western countries. Madri: Fundación Juan March, 2001.

VRÁBLÍKOVÁ, Kateřina. How context matters? Mobilization, political opportunity structures, and nonelectoral political participation in old and new democracies. Comparative Political Studies, v. 20, n. 10, p. 1-27, 2013.

WELZEL, Christian; INGLEHART, Ronald; KLINGEMANN, Hans-Dieter. The theory of human development: a cross-cultural analysis. European Journal of Political Research, v. 42, n. 3, p. 341-379, 2003.

W. K. KELLOGG FOUNDATION. Logic model development guide. Michigan: W. K. Kellogg Founda- 
tion, 2004.

WOND, Tracey; MACAULAY, Michael. Evaluating local implementation: an evidence-based approach. Policy and Society, v. 29, n. 2, p. 161-169, 2010.

YANG, Kaifeng; CALLAHAN, Kathe. Citizen involvement efforts and bureaucratic responsiveness: participatory values, stakeholder pressures, and administrative practicality. Public Administration Review, v. 67, n. 2, p. 249-264, mar./abr. 2007.

Marjorie Angélica Sabioni Ferreira é mestre em administração pela Universidade Federal de Viçosa (UFV) e atua como pesquisadora/colaboradora no Grupo Administração Pública e Gestão Social (APGS). E-mail: marjorie_sabioni@yahoo.com.br.

Marco Aurélio Marques Ferreira fez pós-doutorado em administração pública na Rutgers University, The State University of New Jersey (USA), é doutor em economia aplicada pela Universidade Federal de Viçosa (UFV) e professor do Departamento de Administração e Contabilidade (DAD) da UFV. E-mail: marcoufv1@gmail.com.

Marcelo José Braga fez pós-doutorado na University of California at Davis, UCD (USA), é doutor em economia rural pela Universidade Federal de Viçosa (UFV) e professor do Departamento de Economia Rural (DER) da UFV. E-mail: mjbraga@ufv.br.

Fernanda Maria de Almeida é doutora em economia aplicada pela Universidade Federal de Viçosa (UFV) e professora do Departamento de Administração e Contabilidade (DAD) da UFV. E-mail: fernanda. almeida@ufv.br. 